\title{
Development and validation of a new tool to measure Iranian pregnant women's empowerment
}

N.S. Borghei, ${ }^{1}$ A. Taghipour, ${ }^{2}$ R. Latifnejad Roudsari ${ }^{7}$ and A. Keramat ${ }^{3}$

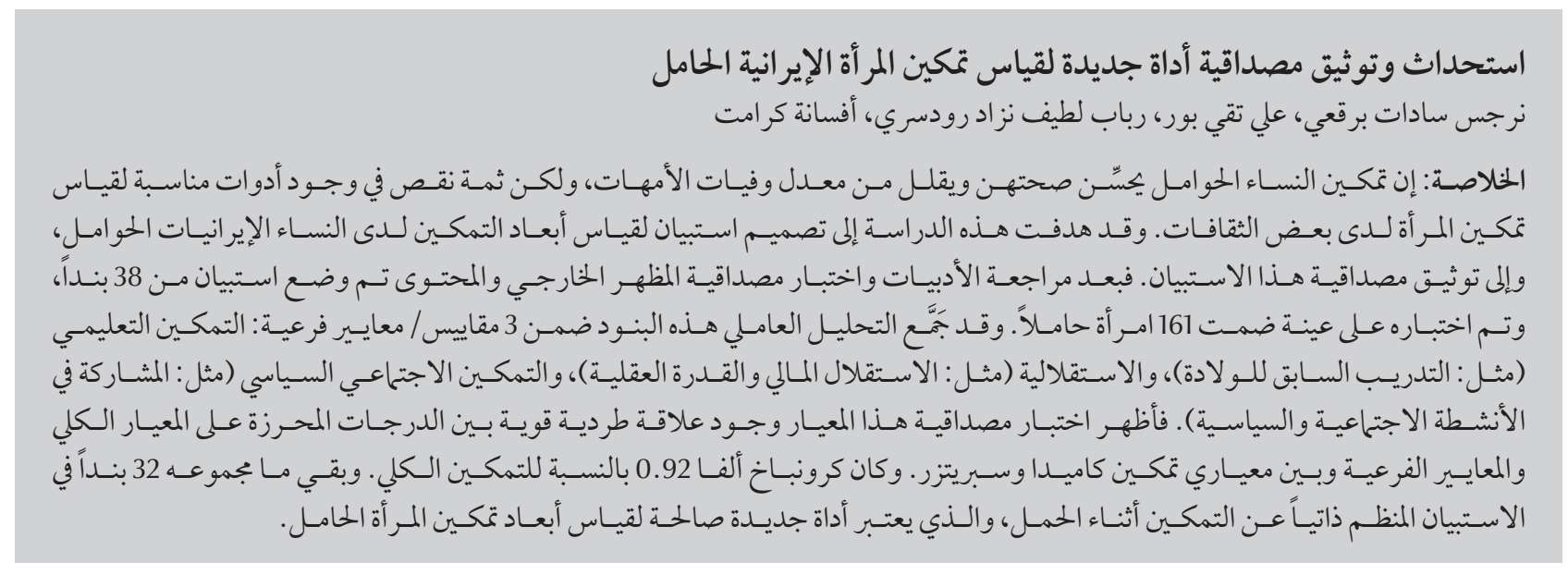

ABSTRACT Empowering pregnant women improves their health and reduces maternal mortality, but there is a lack of suitable tools to measure women's empowerment in some cultures. This study aimed to design and validate a questionnaire for measuring the dimensions of empowerment among Iranian pregnant women. After a literature review, and face and content validity testing, a 38-item questionnaire was developed and tested on a sample of 161 pregnant women. Factor analysis grouped the items into 3 subscales: educational empowerment (e.g. prenatal training), autonomy (e.g. financial independency and mental ability) and sociopolitical empowerment (e.g. involvement in social and political activities). Criterion validity testing showed a strong positive correlation of the total scale and subscales scores with the Kameda and the Spritzer empowerment scales. Cronbach alpha was 0.92 for total empowerment. A total of 32 items remained in the Self-Structured Pregnancy Empowerment Questionnaire, which is a valid new tool to measure the dimensions of pregnant women's empowerment.

Développement et validation d'un nouvel outil pour mesurer l'autonomisation des femmes enceintes iraniennes

RÉSUMÉ L'autonomisation des femmes enceintes améliore leur santé et réduit la mortalité maternelle, mais il manque des outils adaptés pour mesurer l'autonomisation des femmes dans certaines cultures. La présente étude visait à concevoir et valider un questionnaire pour mesurer les dimensions d'autonomisation chez des femmes enceintes iraniennes. Après un examen de la littérature et le test de la validité apparente et de la validité de contenu, un questionnaire en 38 items a été élaboré et testé sur un échantillon de 161 femmes enceintes. Une analyse factorielle a regroupé les items en trois sous-échelles : I'autonomisation par la formation (ex. : la formation prénatale), l'autonomie (ex. : l'indépendance financière et les aptitudes intellectuelles) et l'autonomisation sociopolitique (ex. : l'implication dans les activités sociales et politiques). Le test de la validité des critères a révélé une forte corrélation positive entre les scores de l'échelle totale et des sous-échelles avec les échelles d'autonomisation de Kameda et de Spritzer. Le coefficient alpha de Cronbach était de 0,92 pour l'autonomisation totale. Au total, 32 items ont été conservés dans le Self-Structured Pregnancy Empowerment Questionnaire (Questionnaire autostructuré d'autonomisation des femmes enceintes), qui est un nouvel outil valable pour mesurer les dimensions d'autonomisation des femmes enceintes. 


\section{Introduction}

Empowerment of women during pregnancy gives them control over their own care and health (1) and teaches mothers the necessary skills to handle their pregnancy. These knowledge and skills can help them with their parenting skills in the future (2). Measuring empowerment is a difficult task, however, as empowerment is an internal and hidden attribute that is determined by several important variables, such as culture, religion and the educational and financial status of the mother and her family (3). Therefore, empowerment needs to be assessed through measurable factors such as education, financial stability and decision-making power (4). Furthermore, women can be empowered in many ways and in different fields of their life. The common dimensions of women's empowerment which have been evaluated include financial, social, cultural, legal, political, psychological and family, which cover some of the key terms used to define empowerment such as option, control, power and choice (5-7). Some researchers have measured empowerment with tools based on a small number of questions which evaluate only one or two aspects of empowerment (8-10). Meanwhile, different dimensions of empowerment may be conceptualized differently depending on the context $(4,5)$. Despite the availability of numerous tools to measure women's empowerment, it is still a challenge to find tools that are appropriate for the experiences and culture of each target population $(11,12)$.

The maternal mortality ratio (MMR) in the Islamic Republic of Iran has remained steady in the last 3 years $(2012-15)(13)$. There is some evidence that the MMR in certain developing countries can be reduced via the promotion of women's empowerment during pregnancy ( 8 ). To achieve this goal, we need to be able to measure mothers' empowerment and then to recognize and empower this vulnerable population with related training and educational programmes during pregnancy. No study has been done in the Islamic Republic of Iran to measure empowerment among pregnant women. Kameda and Shimada developed and validated a tool to evaluate prenatal training empowerment (14). Their study, however, evaluated psychological empowerment and was not able to measure other dimensions of empowerment during pregnancy. Considering the importance of reducing the MMR, improving empowerment among pregnant women and the lack of suitable tools for measurement of empowerment among pregnant women in our culture, the present study was conducted to design and validate a tool for measuring the dimensions of empowerment among Iranian pregnant women.

\section{Methods and results}

\section{Study design}

This study was performed in 3 phases. In the first phase, a questionnaire was developed with items covering social, cultural, economic, educational and political empowerment. During the second phase, the face and content validity of the tool were evaluated. In the third phase, the construct validity, criterion validity and internal consistency reliability of the tool were evaluated. Permission for this study was issued by the research committee and regional committee of ethics in Mashhad University of Medical Sciences, 25 January 2014.

\section{Questionnaire development}

To develop the tool, we used the 8 steps of the DeVellis scale development method. The first step was to define what the researcher intends to measure, in this case women's empowerment during pregnancy. The next steps were the generation of an item pool via a literature search and determination of the response format using a 4-point Likert scale (steps 2 and 3) (15).

The inclusion criteria for selecting articles for the literature review for this study were all full-text papers that measured empowerment among Iranian women and were published in English or Persian languages in the last 20 years. The data were collected through databanks, including those of Elsevier, Science Direct and PubMed and Iranian data banks such as Civilica, SID and Magiran. The MeSH terms and keywords used for selecting papers in this study were as follows: "scale development", "empowerment", "measurement", "psychometric properties", "women's empowering", "women's empowerment", "Iran". The studies were assessed for methodological quality using a critical appraisal framework (16) and poor quality studies were excluded. From the total of 1281 papers and articles identified, 103 related to empowerment during pregnancy were reviewed. Of these papers 92 did not measure the dimensions of empowerment and finally 11 articles that measured dimensions of empowerment among Iranian women were selected for the study. A brief description of the findings of the studies and their methods for measuring empowerment in women is provided in Table 1.

Although the social, cultural, economic and political dimensions of the tool were covered by the literature review, no published data were found regarding the measurement of the educational dimension of empowerment during pregnancy. To develop a questionnaire to measure this dimension, we sought help from reproductive health professionals and experts in the Islamic Republic of Iran. After adding the educational items to the questionnaire, the item pool was reviewed (step 4 of DeVellis's scale development method). This extensive literature review resulted in a pool of 64 items. 


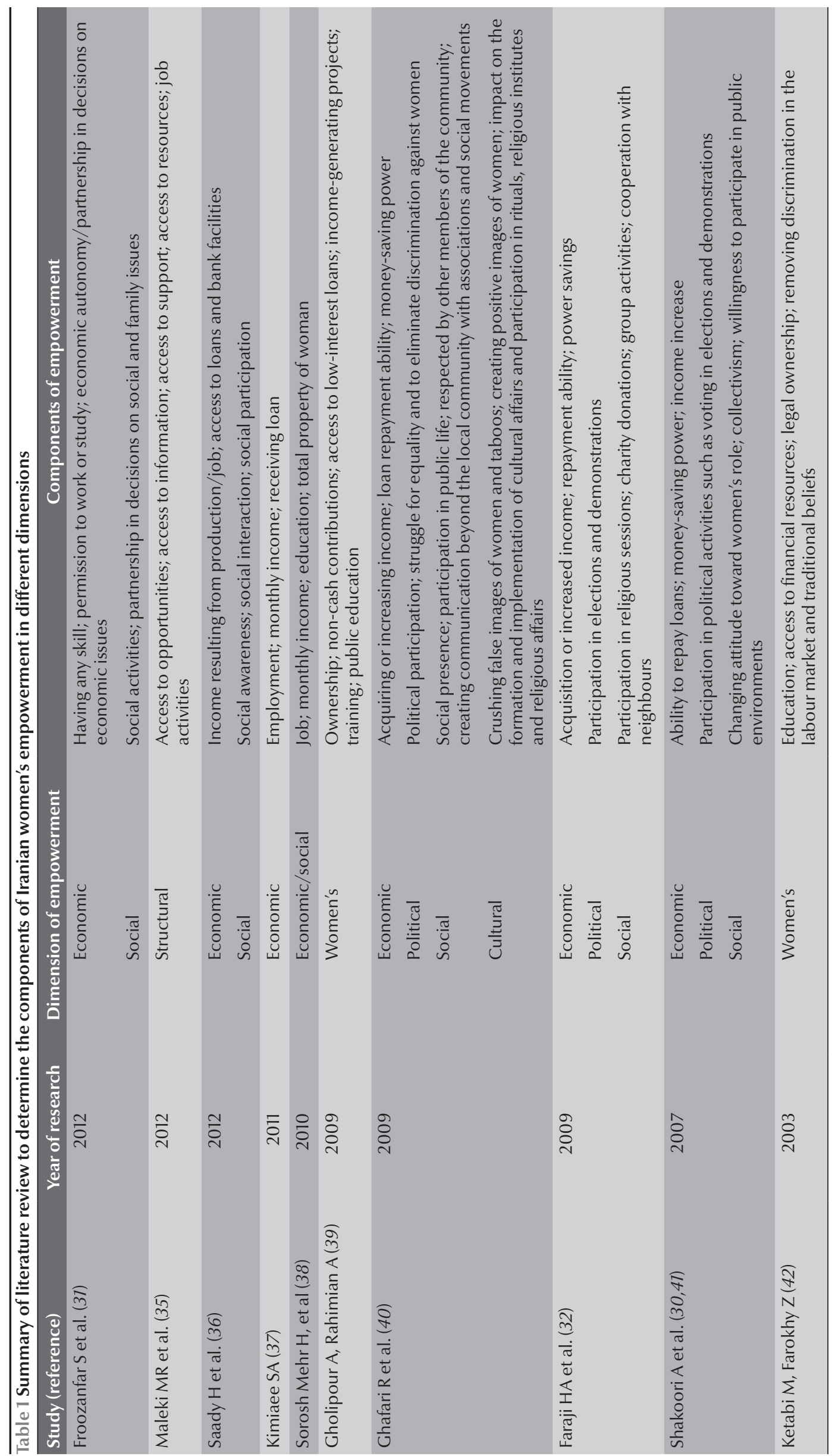




\section{Face and content validity testing}

To measure the validity of the included items (step 5 of DeVellis's method), face and content validity were evaluated.

\section{Face validity}

Face validity was assessed using both qualitative and quantitative methods. In the qualitative phase a sample of the target population were asked to give their feedback on the difficulty, relevance and ambiguity of questionnaire items (17). Items were corrected based on the feedback from a sample of 10 nulliparous women.

In the quantitative phase, impact testing was applied to determine the importance of each phrase. Twelve specialists rated each item on a 5-point Likert scale (very highly important, highly important, important, less important and not important), scored from 1 to 5 . If the resulting impact score was $\leq 1.5$ that phrase was kept and selected for the next step; otherwise it was deleted (17). Finally, the researchers corrected the writing style and logic of the sentences for the questionnaire items.

A total of 7 items were deleted at the face validity stage

\section{Content validity}

The content validity was assessed by calculation of the content validity ratio (CVR) and content validity index (CVI). For this phase, the items were forwarded to 20 reproductive health professionals and empowerment scholars; 12 of the specialists completed the questionnaire.

To calculate CVR, the experts were requested to specify whether each item was necessary for operating a concept in a set of items or not. Also, they were requested to score each item on a scale of 1 to 3, ranging from "not necessary", "useful but not essential" to "essential". Lawshe's CVR formula was used: CVR $=(N e-N / 2) /(N / 2)$, in which $N e$ is the number of panellists indicating "essential" and $N$ is the total number of panellists. The numeric value of CVR is determined by Lawshe's table (based on the number of evaluators i.e. 0.56 for 12 persons). In this study if the result was higher than 0.56 and it was considered to be necessary, the question was kept (18).

The CVIdetermined thatonly 1 item lacked inter-rater proportion agreement about its relevance to the instrument as a whole (19). Questionnaire items rating is typically on a 4-point ordinal scale: $1=$ not relevant, $2=$ somewhat relevant, 3 = quite relevant, 4 = highly relevant. The formula is calculated as follows: (number of experts agreed about an item with 3 and 4 points)/(total number of experts) (20). In this study, items with CVI higher than 0.79 were considered as appropriate, and items rated 0.70-0.79 were corrected. Items with CVI $<0.7$ were excluded $(21)$. The average CVI was $91.3 \%$, which was calculated using the formula: (sum of CVI)/(total number of items) (20).

A further 19 items were deleted at the content validity stage. Finally 38 items remained in the Persian-language Self-Structured Pregnancy Empowerment Questionnaire (SSPEQ).

\section{Construct and criterion validity testing}

For the 6th step, the 38-item SSPEQ was administered to a sample of mothers and then the construct and criterion validity of the questionnaire were examined in the 7th step.

\section{Sampling}

To calculate the sample size for this phase of the study, pilot sampling was conducted and data were obtained from 20 women who were randomly selected from urban health centres. An estimation was made of the correlation of the SSPEQ with other standard questionnaires. Considering $\alpha=0.05$ and $\beta=0.2$, a minimum sample size was estimated to be 141 women.

The questionnaire was then assessed in a cross-sectional study conducted on nulliparous pregnant mothers or mothers who had delivered their babies during the last 2 months in Gorgan city, which is in the centre of Golestan province in the north-west of the Islamic Republic of Iran. The inclusion criteria for the study were ability to read and write and agreement to participate. Multipara and high-risk pregnant women were excluded from the study. Because of the importance of maximum variation for samples, randomized cluster sampling was used to select health centres. Private, educational, and government health centres were included in the study.

We approached 180 nulliparous mothers, selected via random cluster sampling. After exclusion of 19 women (10.3\%) who did not wish to participate, 161 mothers completed the questionnaires.

All ethical considerations were taken into account, such as voluntary participation of mothers after they had been given full information about the purpose of the study, guarantees about the confidentiality of the data and written consent for participation.

\section{Procedure}

The SSPEQ was presented as a selfreporting questionnaire to the mothers. The questionnaire had 2 parts: sociodemographic information [maternal age, gravidity, marriage age, literacy, length of marriage, unwanted pregnancy, family size, ethnicity, job, living status (own or rent house)] and the 38 scale items. It was completed by the 161 selected pregnant women over a 3 -month period in 2014. The data were entered into SPSS, version 16 software for analysis. A great majority of pregnant mothers (92.5\%) were primigravidae and most of them (87.0\%) lived independently with their husbands (Table 2).

\section{Construct validity testing}

Construct validity is the degree to which an instrument measures the construct it is intended to measure (18). To assess 


\begin{tabular}{|c|c|c|}
\hline \multirow[t]{2}{*}{ Variable } & \multicolumn{2}{|c|}{ Value } \\
\hline & Mean (SD) & Range \\
\hline Age (years) & $25.8(4.79)$ & $15-40$ \\
\hline Age at marriage (years) & $22.13(4.46)$ & $12-39$ \\
\hline Duration of marriage (years) & $2.89(1.76)$ & $1-8$ \\
\hline \multirow[t]{2}{*}{ Family size } & $2.28(0.86)$ & $2-7$ \\
\hline & No. & $\%$ \\
\hline \multicolumn{3}{|l|}{ Ethnicity } \\
\hline Fars & 113 & 70.2 \\
\hline Indigenous & 21 & 13.0 \\
\hline Sistani & 16 & 9.9 \\
\hline Turkman & 6 & 3.7 \\
\hline Other & 5 & 3.2 \\
\hline \multicolumn{3}{|l|}{ Literacy } \\
\hline High & 63 & 39.1 \\
\hline Intermediate & 62 & 38.5 \\
\hline Low & 36 & 22.3 \\
\hline \multicolumn{3}{|l|}{ Occupation } \\
\hline Housewife & 129 & 80.1 \\
\hline Employee & 32 & 19.9 \\
\hline \multicolumn{3}{|l|}{ Pregnancy planning } \\
\hline Wanted pregnancy & 147 & 91.3 \\
\hline Unwanted pregnancy & 14 & 8.7 \\
\hline
\end{tabular}

$S D=$ standard deviation .

the construct validity, exploratory factor analysis was used (7th step of DeVellis's method).

The results of exploratory factor analysis together with the varimax rotation method and Kaiser normalization showed that the Bartlett test of sphericity was significant. So, sphericity was rejected $\left(\chi^{2}=4.394, P \leq 0.001\right)$. The Kaiser-Meyer-Olkin measure of sampling for this set of variables was 0.864 , which showed the adequacy of the sample size for factor analysis (22). To reduce the number of factors, eigenvalues were used (eigenvalue > 1) and 5 items $(1,2,8,9,13)$ with factor loading $<4.0$ were excluded. Therefore, the explanatory factor analysis covered 33 out of 38 items.

Factor analysis classified the items in the questionnaire into 3 groups. As can be seen in Table 3, items 24-38, associated with prenatal training, were of the Spritzer and Kameda scales were evaluated using PASS software. The results indicated that there was a strong positive correlation between the SSPEQ total scale and subscales scores and the Spritzer and Kameda scales. A summary of the results is shown in Table 4.

\section{Reliability}

To evaluate internal consistency, Cronbach a coefficient was calculated for all scales and subscales. The minimum accepted Cronbach reliability value for sociopsychological scales is considered to be 0.7 (24). The Cronbach $a$ coefficients were 0.74 for the subscale sociopolitical empowerment, 0.97 for educational empowerment, 0.85 for economic empowerment and 0.92 for total empowerment (Table 5). To increase the internal consistency of the items, the correlation between each item and the total items was evaluated and invalid items were excluded (22). After excluding 1 item, a total of 32 items remained and the 8th step of DeVellis's scale development method was completed.

under the 1st group which called "educational empowerment". Items 13-18, related to financial independency, and items 12, 19 and 20, related to mental ability, were covered under the 2 nd group which was termed "autonomy". Finally, items 3-7 and 10, related to social empowerment, plus 3 items from political empowerment, were covered under the 3 rd group called "sociopolitical empowerment". The 3 factors extracted from factor analysis of variance explained a total of $62.5 \%$ of the variance.

\section{Criterion validity testing}

To evaluate the criterion validity, the Kameda pregnancy empowerment scale and the Spritzer psychological empowerment scale were used as gold standards $(14,23)$. The validated, Persian-language versions of the tools were used. Spearman correlation coefficients of the SSPEQ scores with the scores

\section{Discussion}

The present tool evaluated the sociopolitical, autonomy and educational dimensions of empowerment using a 32 -item questionnaire. The average content validity of the SSPEQ was 0.913 , which is higher than the acceptable value of 0.90 (25). Cronbach a coefficient for the total scale was 0.92 and above 0.7 for all of the subscales. Many researchers have used the same statistical approach and their values are consistent with our results $(14,23,26)$.

In the present study, factor analysis for construct validity was considered as a necessary step to create the tool (15). Some researchers also used this method for construct validity analysis $(14,24)$. For adequate sampling for factor analysis, the Kaiser-Meyer-Olkin value of 
Table 3 Factor loading of the women's empowerment items in the Self-Structured Pregnancy Empowerment Questionnaire among pregnant women $(n=161)$

\begin{tabular}{|c|c|c|c|c|}
\hline \multirow[t]{2}{*}{ Item \# } & \multirow[t]{2}{*}{ Dimension of empowerment/item } & \multicolumn{3}{|c|}{ Factor loadings } \\
\hline & & Factor 1 & Factor 2 & Factor 3 \\
\hline \multicolumn{5}{|c|}{ Social relationships } \\
\hline 1 & I negotiate with others very well & 0.232 & 0.311 & 0.144 \\
\hline 2 & I can persuade others to do what I want & 0.253 & 0.324 & 0.192 \\
\hline 3 & I connect with other people very well & 0.261 & 0.150 & 0.401 \\
\hline 4 & I am aware of my society's problems & -0.017 & 0.015 & 0.564 \\
\hline 5 & I have the spirit of cooperation and interaction with others & 0.244 & 0.178 & 0.479 \\
\hline 6 & I am in touch with organizations and community groups & 0.234 & 0.216 & 0.534 \\
\hline 7 & I work with a group of neighbours to do teamwork & 0.131 & -0.069 & 0.462 \\
\hline 8 & I participate in my own training classes & 0.281 & 0.326 & 0.306 \\
\hline 9 & I have my own position among my peers & 0.143 & 0.263 & 0.312 \\
\hline 10 & I establish sessions to solve the problems of others & 0.233 & 0.311 & 0.402 \\
\hline 11 & I care about teamwork & 0.328 & 0.399 & 0.176 \\
\hline 12 & I have social trust and acceptance & 0.102 & 0.579 & 0.214 \\
\hline \multicolumn{5}{|c|}{ Financial ability } \\
\hline 13 & I am able to manage my personal property such as houses and cars & 0.023 & 0.608 & 0.161 \\
\hline 14 & I have the ability to repay a loan & 0.061 & 0.586 & 0.024 \\
\hline 15 & I have money-saving power & 0.198 & 0.674 & -0.034 \\
\hline 16 & I am able to earn money for my family & 0.118 & 0.848 & 0.013 \\
\hline 17 & I am able to increase my family income & 0.075 & 0.835 & -0.032 \\
\hline 18 & I can spend my personal income any way that I want & 0.075 & 0.727 & 0.116 \\
\hline \multicolumn{5}{|c|}{ Political activity } \\
\hline 19 & I vote for anyone that I want & 0.020 & 0.501 & 0.146 \\
\hline 20 & I can easily participate in my favourite speeches and meetings & 0.084 & 0.486 & 0.374 \\
\hline 21 & I have actively participated in demonstrations and political activities & -0.041 & -0.062 & 0.601 \\
\hline 22 & I can easily become a candidate in town elections & -0.045 & 0.284 & 0.629 \\
\hline 23 & $\begin{array}{l}\text { I can easily participate in political and nongovernmental organizations/ } \\
\text { associations }\end{array}$ & -0.021 & 0.231 & 0.684 \\
\hline \multicolumn{5}{|c|}{ Prenatal training } \\
\hline 24 & Prenatal training empowered me in my life & 0.688 & 0.139 & 0.032 \\
\hline 25 & I acquired useful information about how to overcome pregnancy problems & 0.762 & 0.169 & -0.023 \\
\hline 26 & Prenatal trainings helped me to control my body weight & 0.785 & -0.059 & 0.201 \\
\hline 27 & Prenatal training improved my quality of life & 0.835 & 0.096 & 0.032 \\
\hline 28 & Prenatal training helped me to have better nutrition & 0.866 & 0.087 & 0.089 \\
\hline 29 & With prenatal training, I know about abnormal pregnancy symptoms & 0.828 & 0.156 & 0.130 \\
\hline 30 & $\begin{array}{l}\text { I learned during pregnancy training about when I must go to the hospital } \\
\text { emergency }\end{array}$ & 0.818 & 0.136 & -0.055 \\
\hline 31 & Prenatal training taught me how to prepare for breastfeeding & 0.832 & 0.056 & 0.048 \\
\hline 32 & Prenatal training improved my relationship with others & 0.814 & 0.235 & 0.150 \\
\hline 33 & Prenatal training increased my decision-making power & 0.805 & 0.116 & 0.134 \\
\hline 34 & Prenatal training helped me to take better care of my child & 0.745 & 0.018 & 0.129 \\
\hline 35 & $\begin{array}{l}\text { Prenatal training answered most of my questions about pregnancy and } \\
\text { childbirth }\end{array}$ & 0.865 & 0.059 & 0.116 \\
\hline 36 & Pregnancy training helped me to be psychologically calm & 0.875 & 0.145 & 0.051 \\
\hline 37 & Prenatal training enabled/will enable me to cope with labour pains & 0.789 & 0.14 & 0.232 \\
\hline 38 & $\begin{array}{l}\text { Prenatal training helped me to have a better memory about pregnancy/ } \\
\text { delivery }\end{array}$ & 0.836 & 0.208 & 0.053 \\
\hline
\end{tabular}

Items shown are translations of the Persian-language items.

Shading indicates factor labels. 


\begin{tabular}{|c|c|c|c|c|}
\hline \multirow[t]{2}{*}{ Standard scales } & \multicolumn{4}{|c|}{ SSPEQ dimensions of empowerment } \\
\hline & Sociopolitical & Autonomy & Educational & Total \\
\hline Spritzer psychological empowerment scale & $0.405^{*}$ & $0.483^{*}$ & $0.419^{*}$ & $0.596^{*}$ \\
\hline Kameda empowerment scale & $0.395^{*}$ & $0.436^{*}$ & $0.470^{*}$ & $0.593^{*}$ \\
\hline
\end{tabular}

Spearman correlation coefficient, ${ }^{*} P<0.001$.

sampling adequacy for each set of variables must be higher than 0.8 . Our value was calculated as 0.864 , which shows the adequacy of the sample size (22). The total variance explained was $62.5 \%$, which is sufficient to meet the basic requirements of the phenomenon being investigated $(15,27)$.

After exploratory factor analysis, items about prenatal training were placed in a group called educational empowerment.

The autonomy group of items included the economic and political empowerment items. Most of the articles that we reviewed showed autonomy as one of the most important indicators of women's empowerment, consisting of knowledge, decision-making, and physical, emotional, economic and social selfreliance (28). However, only one study considered financial security by itself to be autonomy empowerment (29). Ahmed et al. measured empowerment scores for developing countries based on a set of women's autonomy questions and found that when a mother has autonomy, she can more easily make decisions about her own health (8). Thus, autonomy should be considered as an indicator for a pregnant women's empowerment.
Some activities that are associated with political and social empowerment were covered under the third group of items: sociopolitical empowerment. Examples of sociopolitical empowerment include being able to vote and to participate in political meetings and elections. Political empowerment for women is directly related to their level of participation in politics, their struggle to attain equal rights and their attempt to remove discrimination against them (7). However, in Iranian society there is a low level of political empowerment, presumably due to low levels of education and political awareness among women. In the studied society, political empowerment is limited to participation in voting and demonstrations (30). Social activity was not considered as a separate part of political empowerment among the studied women, as many researchers considered social support and activities as part of political empowerment $(7,30-32)$.

It is surprising that all of the items related to cultural empowerment were excluded during the validation process, although this was also found in Malhotra et al.'s study (7). Therefore, the cultural dimension of empowerment was not measured in the present study.

Table 5 Cronbach alpha coefficients of the total scale and subscales of the SelfStructured Pregnancy Empowerment Questionnaire (SSPEQ) among pregnant women

\begin{tabular}{lc} 
SSPEQ dimensions of empowerment & Cronbach $\boldsymbol{a}(\%)$ \\
Sociopolitical & 73.5 \\
Autonomy & 85.1 \\
Educational & 96.6 \\
Total & 92.4 \\
\hline
\end{tabular}

Criterion validity analysis indicated that there was a strong positive correlation between the autonomy and educational empowerment dimensions of the SSPEQ and Kameda empowerment but no significant correlation between sociopolitical empowerment and Kameda empowerment. It seems that the Kameda tool was designed to evaluate prenatal training empowerment; therefore, in that study, the sociopolitical dimension had a lower correlation with educational aspects of empowerment. Spritzer's tool is therefore a better scale to measure empowerment. Spritzer's tool showed a high correlation with the subscales of the SSPEQ, which indicates the high validity of the present tool.

As mentioned before, evaluating the level of empowerment is critical for planning training and educational programmes for pregnant women. However, before this study, there was no specific scale that measured all aspects of empowerment in the specific cultural context of Iranian women. Also, during the literature review, it was noticed that different tools $(8-10,14)$ only focussed on certain dimensions of empowerment and there was no tool that evaluated all dimensions of women's empowerment cumulatively. The SSPEQ developed in this study measures the 3 main dimensions of empowerment: sociopolitical, autonomy and educational. We believe that the present tool has the ability to measure empowerment more comprehensively than previous tools.

The initial analysis indicates that the developed tool may be helpful for the precise measurement of empowerment among pregnant women, and it will indicate mechanisms that can 
be applied to improve empowerment during pregnancy with a specific empowerment-based programme. Unfortunately, in the past 3 years, the overall MMR has remain unchanged in the Islamic Republic of Iran, and perhaps it is incorrect to assume that the only barrier to decreasing MMR is related to hospital equipment. In the Islamic Republic of Iran MMR has been shown to be closely related to husband's literacy; for example, in certain ethnic groups, such as the Turkman in Golestan province, the MMR was 2.2 times higher than in other areas of the province (33). Women's lack of power to make decisions about their health or fertility was the main reason for high mortality in that group. It has been proposed that empowering women to take control over their own lives and health can play a major role in reducing MMR (34).

This tool will be open to redevelopment based on the feedback it may receive in the future. Since it is important to obtain the validity of the tool at the international level, the authors propose that similar studies be performed in other populations and in multiparous and high-risk mothers. This tool may be applicable to all young adult women of reproductive age. However, because of the importance of the effect of empowerment on MMR, the author focused on prenatal empowerment.

One of the limitations of this study was the exclusion of multiparous and high-risk pregnant women. Also, the study was limited by the cross-sectional nature of the data. The cross-sectional measures did not capture the dynamics of empowerment and we did not study causal relationships. Despite these limitations, the study's strengths are the use of multiple empowerment indicators, the inclusion of diverse ethnic groups, the use of randomized sampling and the tool's compatibility with the existing tools.

To reach to the goal of the Iranian Government's fifth development plan, we must reduce MMR to 15 per 1000 births by the end of 2015. This requires serious and comprehensive planning (13). Many health professionals believe that maternal deaths are more likely to occur among pregnant women with a low level of empowerment (8). It is recommended for policy-makers to establish an appropriate monitoring system for maternal care programmes, improve the quality of services led by midwives, develop a screening programme to recognize the empowerment needs of pregnant women, establish training and educational programmes for women, and monitor mothers closely during pregnancy. In such a way pregnant women with a low level of empowerment will be recognized and protected, with the ultimate target of reducing MMR.

\section{Acknowledgements}

We express our gratitude towards all the midwives for their cooperation and all the pregnant women who cordially participated in this study and Rouhangiz Mahjoub for English editing of this paper.

Funding: This study was derived from research towards a PhD in Reproductive Health (approved on 15 January 2014, Research Department of Mashhad University of Medical Sciences, grant number 921488). The authors acknowledge the research deputy of Mashhad University of Medical Sciences for approval and financial support.

Competing interests: None declared.

\section{References}

1. Abada T, Tenkorang EY. Women's autonomy and unintended pregnancies in the Philippines. J Biosoc Sci. 2012 Nov;44(6):703-18. PMID:22980635

2. Dumas L. Focus groups to reveal parents' needs for prenatal education. J Perinat Educ. 2002 Summer;11(3):1-9. PMID:17273303

3. Chen M, Mahmud S. Assessing change in women's lives: A conceptual framework. Working Paper No. 2. Dhaka, Bangladesh: BRAC-ICDDR,B Joint Research Project, 1995 (http:// research.brac.net/workingpapers/Working_Paper_2.pdf, accessed 5 September 2015).

4. Mahmud S, Shah NM, Becker S. Measurement of women's empowerment in Bangladesh. World Dev. 2012 Mar 1;40(3):6109. PMID:23637468

5. Malhotra A, Schuler SR. Women's empowerment as a variable in international development. In: Narayan D, editor. Measuring empowerment: cross disciplinary perspectives. Washington (DC): World Bank; 2005.

6. Kishor S. Empowerment of women in Egypt and links to the survival and health of their infant. In: Presser HB, Sen G, editors. New women's empowerment and demographic processes: moving beyond Cairo. Oxford: Oxford University Press; 2000.

7. Malhotra N, Schulder SR, Boender C. Measurement women's empowerment as a variable in international development. Washington (DC): World Bank; 2002.

8. Ahmed S, Creanga AA, Gillespie DG, Tsui AO. Economic status, education and empowerment: implications for maternal health service utilization in developing countries. PLoS One. 2010;5(6):e11190. PMID:20585646

9. Sipsma H, Ofori-Atta A, Canavan M, Udry C, Bradley E. Empowerment and use of antenatal care among women in Ghana: a cross-sectional study. BMC Pregnancy Childbirth. 2014;14:364. PMID:25361525

10. Jennings L, Na M, Cherewick M, Hindin M, Mullany B, Ahmed S. Women's empowerment and male involvement in antenatal care: analyses of Demographic and Health Surveys (DHS) in selected African countries. BMC Pregnancy Childbirth. 2014;14:297. PMID:25174359

11. Bakker L, Van Brakel WH. Empowerment assessment tools in people with disabilities in developing countries: a systematic literature review. Lepr Rev. 2012 Jun;83(2):129-53. PMID:22997690 
12. Zimmerman MA. Psychological empowerment: issues and illustrations. Am J Community Psychol. 1995 Oct;23(5):581-99. PMID:8851341

13. Rahimy T. The basic strategies for improving health and reducing maternal mortality. Paper presented at the National Congress on Strategies for Improving Health and Reducing Maternal Mortality. Tehran, Islamic Republic of Iran, 27-28 September 2014 (http://www.immc2014.ir, accessed 5 September 2015) [in Persian].

14. Kameda Y, Shimada K. Development of an empowerment scale for pregnant women. Journal of the Tsuruma Health Science Society Kanazawa University. 2008;32(1):39-48.

15. DeVellis RF. Factor analysis, scale development theory and application. Appl. Soc. Res. Method Ser. 2003;26:10-137.

16. Guyatt GH, Sackett DL, Cook DJ. Users' guides to the medical literature. II. How to use an article about therapy or prevention. A. Are the results of the study valid? Evidence-Based Medicine Working Group. JAMA. 1993 Dec 1;270(21):2598-601. PMID:8230645

17. Juniper EF, Guyatt GH, Streiner DL, King DR. Clinical impact versus factor analysis for quality of life questionnaire construction. J Clin Epidemiol. 1997 Mar;50(3):233-8. PMID:9120521

18. Lawshe $\mathrm{CH}$. A quantitative approach to content validity. Person Psychol. 1975;28:563-75.

19. Wynd CA, Schmidt B, Schaefer MA. Two quantitative approaches for estimating content validity. West J Nurs Res. 2003 Aug;25(5):508-18. PMID:12955968

20. Davis LL. Instrument review: Getting the most from your pane of experts. Appl Nurs Res. 1992;5:194-7.

21. Hyrkäs K, Appelqvist-Schmidlechner K, Oksa L. Validating an instrument for clinical supervision using an expert panel. Int J Nurs Stud. 2003 Aug;40(6):619-25. PMID:12834927

22. Munro BH. Statistical methods for health care research. 4th ed Philadelphia: Lippincott. Williams \& Wilkins; 2005.

23. Spreitzer GM. Psychological empowerment in the workplace: dimensions, measurement, and validation. Acad Manage J. 1995;38(5):1442-65.

24. Uner S, Turan S. The construct validity and reliability of the Turkish version of Spreitzer's psychological empowerment scale. BMC Public Health. 2010;10:117. PMID:20214770

25. Polit DF, Beck CT. The content validity index: are you sure you know what's being reported? Critique and recommendations. Res Nurs Health. 2006 Oct;29(5):489-97. PMID:16977646

26. Nunnally J. Psychometric theory. 2nd ed. New York: McGrawHill; 1978.

27. Hooper D. Exploratory factor analysis. Approaches to quantitative research theory and its practical application: a guide to dissertation students. Cork. Ireland: Oak Tree Press; 2012.

28. Jejeebhoy SJ. Women's education, autonomy, and reproductive behaviour: experience from four developing countries. International Studies in Demography. Oxford: Clarendon Press; 1995.
29. Hashemi SM, Sidney RS, Riley AP. Rural Credit Programs and Women's Empowerment in Bangladesh. World Dev. 1996;24(4):635-53.

30. Shakouri A, Rafat Jah M, Jafari M. Women's empowerment component and explain influencing factors. Women in Development and Politics. 2007;5(1):1-26 [in Persian].

31. Froozanfar S, Majlessi F, Rahimi Forroshani A, Pour Reza A. Assessment of the relationship between empowerment and reproductive behavior. Daneshvar. Scientific Research Journal of Shahed University. 2012;99:1-9 [in Persian].

32. Faraji Sabokbar HA, Khaki A, Nemati M. Evaluation of the role of ICT in rural women empowerment. Case study: Gharn Abad village. Geography. 2009;7(22):159-75 [in Persian].

33. Rahimian $\mathrm{SH}$. A study of the relationship between maternal mortality and ethnicity in Golestan province in Iran. Paper presented at the National Congress on Strategies for Improving Health and Reducing Maternal Mortality. Tehran, Islamic Republic of Iran, 27-28 September 2014 (http://www.immc2014. ir, accessed 5 September 2015) [in Persian].

34. Pandey S, Singh M. Women empowerment and personal values as predictors of reproductive health. J Indian Acad Appl Psychol. 2008;34(2):309-16.

35. Maleki MR, Gohari MR, Ghorbanian A. Relationship between structural empowering and nurses' readiness for change. Iran Journal of Nursing. 2012;25(76):10-8.

36. Saadi H, Fami Shabanali H, Latifi S. Assessment of the economic and social empowerment of female carpet weavers in rural and factors affecting it (case study in Hamadan province). Journal of Women in Development and Politics. 2012;10(2):107-26.

37. Kimiaee S. Methods used for empowering head-of-household women. Social Welfare. 2011;11(40):63-92 [in Persian].

38. Soroush Mehr H, Rafiee H, Kalantari KH, Shaban Fami H. Assessment of the socioeconomic status of rural women and the factors affecting its recovery (case study in Hamadan city). Rural Studies. 2010;1(1) [in Persian].

39. Gholipour A, Rahimian A. Economic factors, cultural and educational empowerment of household women. Journal of Social Welfare. 2011;11(40):29-62 [in Persian].

40. Ghafari R, Darabi H, Jahangiri P. An overview with emphasis on the empowerment of female-headed households. Paper presented at the Second Conference on Women's Empowering and the Empowerment of Women Heads of Household. Tehran, Islamic Republic of Iran, Summer 2010 [in Persian].

41. Shakouri A. Policy Advocacy and Empowerment of Women. Journal of the Faculty of Literature and Humanities.2008;61:129-59 [in Persian].

42. Ketabi M, Yazdkhasti BZ, Farokhy Rastaby Z.. Conditions and obstacles of women's empowerment: a case study in Isfahan city. Research Bulletin of Isfahan University. 2005;19(2):1-20 [in Persian]. 